\title{
The effect of TQM on customer satisfaction in higher education
}

\author{
Roholah Shahdadnejad $^{\mathrm{a}}$ and Younos Vakil Alroaia ${ }^{\mathrm{b}^{*}}$
}

${ }^{a}$ Master Student, Department of Management, Semnan Branch, Islamic Azad University, Semnan, Iran

${ }^{b}$ Assistant Professor and Chairman, Department of Management, Semnan Branch, Islamic Azad University, Semnan , Iran , P.O.Box $35145-175$ \begin{abstract}
A B S T R A C T
Total quality management (TQM) plays an important role on improving educational systems. In this paper, we present an empirical study to investigate the effect of TQM components on customer satisfaction in one of higher educational organizations in South East part of Iran called Qeshm. The proposed study investigates the effects of five TQM components including tangible, attitude, reliability, content and mode of delivery on customer satisfaction. The study designs a questionnaire consists of 37 questions and distributes it among a sample of university students and professors. Cronbach are calculated for significance, attitude, reliability, content and mode of delivery were $0.84,0.83,0.91,0.90$ and 0.83 , respectively. The results of our survey are investigated using Pearson correlation ratios as well as regression analysis and the results indicate that all five components influence customer satisfaction, significantly.
\end{abstract}

\section{Introduction}

Education is a valuable resource for the development of any society and high quality schools is considered as an integral part of political speech and administrative management of higher educations (Reed et al., 1996; Sun, 1999; Rahman, 2004; Rahman \& Bullock, 2005). Quality also plays an important role on increasing customer satisfaction and increasing market share. The success of all organizations and institutions, such as manufacturing or services, profit or nonprofit, public or private, is influenced by several factors where one of the most important customer satisfaction is to achieve excellence in business. Today, customer satisfaction is one of the basic requirements for quality management systems and excellence models (Parasuraman et al.; Parasuraman et al., 1991). It is normally a difficult task for locating different characteristics to evaluate quality of services because the nature of work is very complex. This requires the use of an appropriate tool for evaluating the quality of an intangible product such as educational systems. Ghasemi et al. (2012) prioritized the main parameters affecting Iranian polyester company's quality using total quality management. 
Baykal et al. (2005) investigated relationships between satisfaction and expectations among students in a nursing college in Turkey. The results demonstrated that student satisfaction increased in 2001 but decreased in the second year. They reported that student who participated in this survey strongly believed that it was possible for improvement in the present education system and recreational activities. Ozkan and Koseler (2009) proposed a conceptual e-learning assessment model, hexagonal elearning assessment model (HELAM) suggesting a multi-dimensional approach for LMS evaluation via six dimensions. Their explanatory factor analysis demonstrated that each of the six dimensions of their proposed model had a significant impact on the learners' perceived satisfaction. There are many other studies associated with measuring the quality of educational systems and the proposed study of this paper is dedicated to use TQM based methods for measuring the effects of different factors on customer satisfaction in one of educational organizations located in free zones in Iran. Saeidipou (2012) performed an empirical investigation on the effect of organizational climate on organizational commitment. The results of the study showed that there was a significant relationship between the components of role and paying enough attention to goals, the variable organizational climate, and the whole variable dimensions of organizational commitment.

The organization of this paper first presents details of our proposed study in section 2 while the results of our findings are given in section 3. Finally, concluding remarks are given in the last to summarize the contribution of the paper.

\section{The proposed model}

There are five hypotheses for the proposed study of this paper as follows,

1. There is a positive relationship between tangible factors and customer satisfaction.

2. There is a positive relationship between attitude factors and customer satisfaction.

3. There is a positive relationship between reliability factors and customer satisfaction.

4. There is a positive relationship between content and customer satisfaction.

5. There is a positive relationship between mode of delivery factors and customer satisfaction.

For the proposed model of this paper, we have adopted a questionnaire, which consists of 37 questions. In our survey, the first five questions are associated with general and personal perspective of the participants, questions 6 to 15 were related with tangible, questions 16 to 19 were related to attitude, questions 20 to 28 were about reliability, questions 29 to 33 studied content issues and finally, questions 34 to 37 studied transfer method. Cronbach alpha was calculated as 0.97 , which is significant and validates the overall performance of the questionnaire. Detailed Cronbach were calculated for significance, attitude, reliability, content and mode of delivery were $0.84,0.83,0.91$, 0.90 and 0.83 , respectively. The population of this survey consists of 400 students and 60 university professors. We use the following formula to calculate the minimum number of sample size for students,

$$
n=\frac{N \times z_{\alpha / 2}^{2} \times p \times q}{\varepsilon^{2} \times(N-1)+z_{\alpha / 2}^{2} \times p \times q},
$$

where $N$ is the population size, $p=1-q$ represents the yes/no categories, $z_{\alpha / 2}$ is CDF of normal distribution and finally $\varepsilon$ is the error term. Since we have $p=0.5, z_{\alpha / 2}=1.96$ and $N=400$, the number of sample size is calculated as $n=160$ and in this survey, 180 questionnaires were distributed and 156 questionnaires were collected. Similarly, the sample size for university professors was calculated as 45 and due to some existing limitation, the study distributed 39 questionnaires among university profwssors and could manage to collect all of them. The propsoed study of this paper uses Pearson correlation ratio to study the relationship between TQM and other factors. In our survey Pearson correlation ratio between customer satisfaction and TQM was 0.876 with P-value $=0.000$, which means there is a strong correlation between these two items. In addition, Pearson corrlation ratio between tangible and customer satisfaction was 0.538 with P-value of 0.000 . In addition, Pearson 
correlation value was 0.732 with P-value of 0.732 between customer satisfaction and trust while this ratio was 0.788 between attitide and customer satisfaction. Finally, the Pearson corellation ratios for content and mode of delivery with customer satisfaction were 0.802 and 0.852 , respectively. These ratios are statistically significance and we can rely on the results of our survey.

\section{The results}

In order to understand the difference between five mentioned components and gender we have used mean and standard deviations of the data are calculated, summarized in Table 1.

Table 1

The summary of mean and standard deviation

\begin{tabular}{lccccc}
\hline Variable & Gender & Number & Mean & Standard deviation & Standard error \\
\hline \multirow{2}{*}{ Tangible } & Male & 118 & 31.12 & 9.3819 & 0.86367 \\
\hline \multirow{3}{*}{ Attitude } & Female & 77 & 30.91 & 6.65737 & 0.75868 \\
\hline \multirow{2}{*}{ Reliability } & Male & 113 & 13.62 & 5.2971 & 0.49831 \\
\hline \multirow{3}{*}{ Content } & Female & 72 & 13.76 & 4.80754 & 0.56657 \\
\hline \multirow{2}{*}{ Mode of delivery } & Male & 118 & 31.6 & 10.85344 & 0.99914 \\
\hline
\end{tabular}

Based on the results of Table 1, we can observe that there are some differences between female and male but this difference is not statistically significance, $t$-student $=0.125, \mathrm{P}$-value $=0.108$. Therefore, gender does not seem to play an important role on survey factors. Table 2 shows details of our survey on each component of the survey.

\section{Table 2}

The summary of t-student values for five components of the survey in terms of gender

\begin{tabular}{lccc}
\hline Variable & Frequency & P-value & t-value \\
\hline Tangible & 8.742 & 0.003 & 0.170 \\
Attitude & 0.483 & 0.488 & -0.187 \\
Reliability & 0.549 & 0.460 & 0.970 \\
Content & 1.985 & 0.161 & -0.467 \\
Mode of delivery & 2.610 & 0.108 & 0.125 \\
\hline
\end{tabular}

The results of Table 2 also confirm that none of the variables is statistically significance and gender has no impact on any components of TQM model. The other important issue is to see whether there is any significant difference on components of TQM between students and university professors. Our results indicate that although there were some small differences but the difference was not statistically significance. Table 3 demonstrates details of our survey.

Table 3

Summary of the results of mean and standard deviation

\begin{tabular}{llllll}
\hline Variable & Gender & Number & Mean & Standard deviation & Standard error \\
\hline \multirow{3}{*}{ Tangible } & University professor & 39 & 35.26 & 9.15 & 1.46 \\
\hline \multirow{3}{*}{ Attitude } & Student & 156 & 30 & 7.88 & 0.63 \\
\hline \multirow{3}{*}{ Reliability } & University professor & 38 & 16.77 & 4.43 & 0.72 \\
\hline \multirow{3}{*}{ Content } & Student & 147 & 12.88 & 4.97 & 0.41 \\
\hline \multirow{2}{*}{ Mode of delivery } & University professor & 39 & 37.82 & 10.71 & 1.71 \\
\hline & Student & 156 & 29.33 & 9.32 & 0.75 \\
\hline
\end{tabular}


Again, our investigation on the difference on mean and standard deviation between university professors and students does not lead us to believe there is any difference since t-student is not statistically meaningful. Table 4 demonstrates the summary of our results.

\section{Table 4}

The summary of t-student values for five components of the survey in terms of job position

\begin{tabular}{lccc}
\hline Variable & Frequency & P-value & t-value \\
\hline Tangible & 1.38 & 0.241 & 3.62 \\
Attitude & 1.725 & 0.191 & 4.40 \\
Reliability & 0.322 & 0.571 & 4.93 \\
Content & -0.1918 & 0.663 & 4.65 \\
Mode of delivery & 2.543 & 0.112 & 3.74 \\
\hline
\end{tabular}

The results of Table 4 also confirm that none of the variables is statistically significance and gender has no impact on any components of TQM model.

In order to investigate the difference between various components, we use F-statistic ratio to see whether there is any difference among different components of the survey, Table 5 demonstrates the results of our survey in terms of mean, and Table 6 demonstrates the results of ANOVA test.

Table 5

The mean of five components in different departments

\begin{tabular}{lccccc}
\hline & Tangible & Attitude & Reliability & Content & Mode of delivery \\
\hline Social science & 33.44 & 15.47 & 34.04 & 18.68 & 12.96 \\
Basic science & 31.49 & 13.83 & 29.98 & 17.35 & 12.39 \\
Engineering & 28.19 & 11.77 & 28.49 & 15.76 & 10.96 \\
Agriculture & 30.97 & 13.57 & 31.60 & 15.97 & 12.83 \\
\hline
\end{tabular}

Table 6

The summary ANOVA test for five components of the survey $(\mathrm{df}=3$ )

\begin{tabular}{lccc}
\hline Variable & Mean square & f-value & p-value \\
\hline Tangible & 240.89 & 3.55 & 0.015 \\
Attitude & 111.14 & 4.52 & 0.004 \\
Reliability & 289.29 & 2.87 & 0.037 \\
Content & 89.15 & 2.23 & 0.086 \\
Mode of delivery & 40.33 & 1.78 & 0.152 \\
\hline
\end{tabular}

The results of one-way ANOVA test shows that the mean of tangible is different among various departments when the level of significance is five percent. Similar results also hold for attitude, reliability but the results of ANOVA test does not confirm any difference for two components of content and mode of delivery. Finally, we have performed a regression analysis to measure the effects of various components on customer satisfaction and Table 7 summarizes the results of our survey.

Table 7

The summary of regression analysis

\begin{tabular}{lccccccc}
\hline & Coefficient & Standard error & Standard coefficient & t-student & P-value & Lower & Upper \\
\hline Intercept & 0.494 & 0.574 & & 0.861 & 0.39 & 1.626 & 0.68 \\
Tangible & 0.021 & 0.022 & 370. & 0.952 & 0.342 & 0.063 & 0.02 \\
Attitude & 0.264 & 0.044 & 0.273 & 6.003 & 0 & 0.177 & 0.35 \\
Reliability & 0.086 & 0.021 & 0.188 & 4.128 & 0 & 0.045 & 0.127 \\
Content & 0.17 & 0.036 & 0.222 & 4.721 & 0 & 0.099 & 0.241 \\
Mode of delivery & 0.412 & 0.052 & 0.4 & 7.896 & 0 & 0.309 & 0.515 \\
\hline
\end{tabular}


According to the results of Table 7, except the first component, tangible, other variables maintain meaningful values when the level of significance is five percent. In other words, an increase of one unit in attitude, reliability, content and mode of delivery will increase customer satisfaction for 0.262 , 0.086, 0.17 and 0.412 , respectively.

In summary, the results of our survey have disclosed that there is a strong correlation between different components of this survey and this is consistent with the results of Ozkan and Koseler (2009). The results also indicate that mode of delivery maintains the minimum and reliability maintains the highest mean. There were five hypotheses associated with the proposed study of this paper.

The first hypothesis of this survey investigates the relationship between tangible and customer satisfaction and the results of this survey confirmed this relationship, which is consistent with other investigations (Faruk unal, 2000l; Baykal et al., 2005; Boylston \& Jackson, 2008).

The second part of our survey is associated with the relationship between reliability and customer satisfaction and our results have confirmed this relationship, positively, while are also consistent with findings of Baykal et al. (2005). In addition, the impact of reliability was statistically significant among different departments but gender had no significant impact on. The third hypothesis of this survey investigates the relationship between attitude and customer satisfaction and the results of this survey confirmed this relationship. Again, we found that the impact of reliability was different among various department but it gender had no impact on. The fourth hypothesis of this survey investigated the relationship between content and customer relationship and the results of survey have indicated that there were some positive and meaningful relationships between these two components. Finally, the last hypothesis of this survey considered the relationship between mode of delivery and customer relationship and the results of the survey have confirmed this relationship.

\section{Conclusion}

In this paper, we have presented an empirical study to measure the impact of different factors on customer satisfaction. The proposed study of this paper was performed in one of educational systems located in free zones of Iran. The proposed study investigated the impacts of five TQM components including tangible, attitude, reliability, content and mode of delivery on customer satisfaction. The results of our survey were investigated using Pearson correlation ratios as well as regression analysis and the results indicated that all five components influenced customer satisfaction, significantly.

\section{Acknowledgment}

The authors are grateful for cooperation of university professors as well as students for fulfilling this survey.

\section{References}

Abtahi, S. H., \& Saadi, M. R. (2012). A conceptual model for empowering bank's human resources: A case study of Tejarat bank of Iran. Management Science Letters, 2, 979-988.

Baykal, U., Sokmen, S., Korkmaz, S., \& Akgun, E. (2005). Determining student satisfaction in a nursing college. Nurse Education Today, 25(4), 255-262.

Boylston, M.T., \& Jackson, C. (2008). Adult student satisfaction in an accelerated RN-to-BSN program: a follow-up study. Journal of Professional Nursing, 24(5), 285.295.

Faruk unal, O. (2000). Application of Total Quality Management in Higher Education. Qafaz University. 
Ghasemi, E., Jamali, B., \& Nouri, P. (2012). Technology change priorities influencing competition quality promotion: Case study of IranKeaton Polyester Manufacturing Company. Management Science Letters, 2, 1913-1920.

Ozkan, S., \& Koseler, R. (2009). Multi-dimensional students' evaluation of e-learning systems in the higher education context: An empirical investigation. Computers \& Education, 53, 1285-1296.

Parasuraman, A., Zeithamel, V. A., \& Berry, L. (1985). A conceptual model of service quality and itsimplication for future research. Journal of Marketing, 49(4), 41-50.

Parasuraman, A., Zeithamel, V. \& Berry, A. (1991). Understanding customer expectations of service. SloanManagement Review, 32(3), 39-49.

Prajogo, D.I., \& Sohal, A.S. (2004). The multidimensionality of TQM practices in determining quality and innovation performance-an empirical examination. Technovation, 24, 443-453.

Rahman, S. (2004). The future of TQM is past. Can TQM be resurrected? Total Quality Management, 15 (4), 411-422.

Rahman, S., \& Bullock, P. (2005). Soft TQM, hard TQM, and organizational performance relationships: an empirical investigation. Omega, 33, 73-83.

Reed, R., Lemak, D.J., \& Montgomery, J.C. (1996). Beyond Process: TQM content and firm performance. Academy of Management Review, 21 (1), 173-201.

Saeidipou, B. (2012). A study on the effect of organizational climate on organizational commitment: A case study of educational system. Management Science Letters, 3(1), 181-194.

Sun, H. (1999). Diffusion and contribution of total quality management: an empirical study in Norway. Total Quality Management, 10 (6), 901-914. 